\title{
Improving aspirin prophylaxis after myocardial infarction in primary care: collaboration in multipractice audit between primary care audit group and health authority
}

\author{
Kamlesh Khunti, Ross Sorrie, Siobhan Jennings, Azaar Farooqi
}

The Antiplatelet Trialists' Collaboration provided convincing evidence of benefits of aspirin prophylaxis in patients after myocardial infarction, ${ }^{1}$ but many such patients do not receive it. ${ }^{23}$ Since most patients are followed up in primary care, practices need to implement methods of improving aspirin prophylaxis in these patients. The aim of this multipractice audit led by a primary care audit group was to assess and improve levels of prescribing of prophylactic aspirin for patients after myocardial infarction in Leicestershire.

\section{Subjects, methods, and results}

All Leicestershire practices $(\mathrm{n}=154)$ were invited to take part and were offered six hours' postgraduate allowance for completing the full audit cycle. The health authority supplied data to the participating practices on currently registered patients who had been discharged after myocardial infarction over the past five years. These data were retrieved from the hospital information system and were checked against the list of registered patients. Patients who had died and those who had moved away were removed from the list. Practices were guaranteed anonymity on their audit results.

A retrospective record review was carried out in general practice by the practice staff, who were asked to check the status of each patient relating to his or her eligibility for aspirin prophylaxis and any contraindications to aspirin. All results were entered on to piloted data collection forms that were returned to the audit group for analysis. Practices received aggregated feedback of results of the first phase and were encouraged to develop multiple strategies for improvement in response to their results. Strategies for improvement included tagging the notes and inviting patients to attend for review. A reaudit was carried out after six months.

Forty five practices with 149 partners (mean 3.3; range 1-8) took part in the audit. Ten practices were single handed, 31 had two to five partners, and four had six or more partners. The practices covered 270036 patients, of whom 1264 (72.8\% male) were eligible to be included in the audit. The table shows the results of the first audit (phase 1) and the reaudit after feedback and implementation of change (phase 2).

\section{Comment}

Our study shows that just over $15 \%$ of patients received suboptimal treatment in the first audit, a standard similar to those observed in recent surveys.. ${ }^{2}$ Previous audits, however, did not implement change and complete the audit cycle. In contrast, our study shows that multipractice audit and feedback of comparisons between peers leads to improvements in the care of patients after myocardial infarction. Our study has several limitations: the health authority could provide an

Aspirin prophylaxis in patients after myocardial infarction in 45 general practices in Leicestershire

\begin{tabular}{lccc} 
& $\begin{array}{c}\text { Phase 1* } \\
(\mathbf{n = 1 2 6 4 )}\end{array}$ & $\begin{array}{c}\text { Phase 2 } \\
(\mathbf{n = 1 2 5 8 ) \dagger}\end{array}$ & Significance \\
\hline No of patients taking aspirin & 957 & 1058 & - \\
\hline No (\%) of patients with contraindication to aspirin & $127(10.0)$ & $163(13.0)$ & - \\
\hline $\begin{array}{l}\text { \% of patients treated, excluding those with } \\
\text { contraindication }(95 \% \mathrm{Cl})\end{array}$ & $84.2(81.9$ to 86.2$)$ & $96.6(95.4$ to 97.6$)$ & $\begin{array}{c}\chi^{2}=97.1 \\
\mathbf{P}<0.0001\end{array}$ \\
\hline
\end{tabular}

${ }^{*}$ All eligible patients were receiving aspirin in 12 practices.

tExcludes six patients who had been given incorrect diagnosis, who had died, or who had moved away.

accurate list of patients after myocardial infarction only in the past five years; all practices were self selected; and the record review was carried out by the practices. The results therefore probably overestimate the quality of care of patients after myocardial infarction.

Participation in audit is influenced by many factors, with lack of time and skill being two of the common barriers. ${ }^{4}$ A time consuming and difficult part of undertaking audit is compiling a register of patients with the condition being audited. In our study the health authority made this register readily available to the practices.

The white paper The New NHS places great emphasis on improving quality of care with the introduction of clinical governance and clinical effectiveness. ${ }^{5}$ Health authorities will have a key role in implementing clinical governance and ensuring that clinicians are encouraged to move towards evidence based practice. Our study shows that collaborative audit with anonymised feedback can reduce the gap between current practice and practice that is evidence based.

We thank all the practices that participated in the audit.

Contributors: SR, JS, and FA were responsible for the audit design.JS supplied the list of patients after myocardial infarction to the practices. KK gave feedback to the practices after the first phase of the audit and suggested methods of implementing change. KK and SR were responsible for the data analysis. KK was responsible for the initial drafting of the paper, and all authors made contributions to subsequent drafts. KK is the guarantor.

Funding: Leicestershire Primary Care Audit Group is an independent audit group and is funded by Leicestershire Health Authority. The Clinical Governance Research and Development Unit is core funded by Leicestershire Health Authority and Trent region.

Competing interests: None declared.

1 Antiplatelets Trialists' Collaboration. Collaborative overview of randomised trials of antiplatelet therapy. I. Prevention of death, myocardial infarction, and stroke by prolonged antiplatelet therapy in various infarction, and stroke by prolonged antip
categories of patients. BMJ 1994;308:81-106.

2 Whitford DL, Southern AJ. Audit of secondary prophylaxis after myocardial infarction. BMJ 1994;309:1268-9.

3 Bradley F, Morgan S, Smith H, Mant D for the Wessex Research Network (WReN). Preventative care for patients following myocardial infarction. Fam Pract 1997;14:220-6.

4 Chambers R, Bowyer S, Campbell I. Investigation into the attitudes of general practitioners in Staffordshire to medical audit. Quality in Health Care 1996;5:13-9.

5 Secretary of State for Health. The new NHS. London: Stationery Office, 1997. (Cm3807.)

(Accepted 8 March 1999)
Clinical

Governance

Research and

Development Unit,

Department of

General Practice

and Primary Health

Care, University of

Leicester, Leicester

LE5 4PW

Kamlesh Khunti,

clinical lecturer

Leicestershire

Primary Care Audit

Group, Leicester

General Hospital,

Leicester LE5 4PW

Ross Sorrie,

manager

Azaar Farooqi,

chairman

Leicestershire

Health Authority,

Leicester LE5 4QF

Siobhan Jennings,

consultant in public

health medicine

Correspondence to:

Dr Khunti

kk22@le.ac.uk

BMJ 1999;319:297 